\title{
Phyto-chemicals and Hypoglycaemia in Diabetics
}

\author{
Adegbenga B Ademolu* \\ Medicine Department, Lagos State University Teaching Hospital, Nigeria \\ *Corresponding author: Adegbenga B Ademolu, Medicine Department, Lagos State University Teaching Hospital, Lagos, Nigeria
}

Submission: November 13, 2017; Published: April 11, 2018

\begin{abstract}
Abbreviations: VLDL: Very Low Density Lipoprotein; AST: Aspartate Amino Transferase; ALT: Alanine Amino Transferase; GGT: Gamma Glutamyl Tran peptidase enzymes; TC: Total Cholesterol; TG: Triglycerides; LDL-C: Low Density Lipoproteins; SOD: Super Oxide Dismutase; GPx: Glutathione Peroxidise; CAT: Catalase
\end{abstract}

\section{Introduction}

Photo chemicals are chemical compounds produced by plants. They are endocrine distruptors known for ages to affect blood glucose metabolism. Blood glucose homeostasis is a balance between gluconeogenesis, glycogenolysis and glycolysis among others. Gluconeogenesis which is the production of glucose from non carbohydrate source is influenced by lip genesis. Phyto chemical effects on glucose metabolism may enhance or inhibit these processes. Phyto-chemical enhancing glycolysis results in hypoglycaemia or inducing gluconeogenesis or glycogenolysis causing hyperglycaemia.

These hyperglycaemic or hypoglycaemic effects of these Phytochemicals have varying effects on the internal milieu with varying endocrine Sequelae. Phyto-chemicals and their derived products have been an extraordinary source of compounds with therapeutic and drug development potential [1]. These molecules are novel and complex structures that can be used in their original form, or can serve as lead molecules to develop derivatives with higher specificity and fewer side effects [2]. The World Health Organization has been particularly attentive to the potential offered by herbal medicine, the main subfield of traditional medicine practiced in different countries [3]. This review focuses on the hypoglycaemic effects of some Phyto-chemicals.

\section{Carica papaya $L$}

Carica papaya $L$, is an herbaceous plant with prominent leaves $(20-60 \mathrm{~cm}$ long), and is a member of the Caricaceae family, indigenous to the tropical region of Mexico, Central America and northern South America. C. papaya is distributed throughout the tropics and subtropics where it is extensively cultivated. The characterized metabolites from the plant are chitinase, glutaminyl cyclase and cysteine endopeptidases of class-II and III from Carica latex [4,5]; linalool in fruit pulp, and alkaloids such as carpaine, pseudocarpaine, dehydrocarpaine I and II [6]; and kaempferol and quercetin [7] in the leaves. C. papaya leaves are used traditionally by diabetic's patients in the region of cintalapa, Chiapas, Mexico. Photochemical screening of the extract reveals the presence of different compounds. However the pharmacological activities of $C$. papaya leaves cannot be determined solely by the result of the photochemical analysis. Some of these phytocompounds are responsible for the hypoglycaemic and hypolipemic effects in diabetic rats. Several studies report that these biological activities might be manifest due to the presence of flavonoids, alkaloids, steroids and quinines [8].

Additionally, to its hypoglycaemic effects, C. papaya chloroform extract also caused a decrease in the concentration of serum triacylglycerides and total cholesterol in diabetic rats. High Density Lipoprotein-Cholesterol levels decrease in diabetes rats without treatment and even more in diabetic rats that received insulin. Interestingly the mechanism by which this decrease in lipids concentration occurs could be explained by stimulation of lipolysis and higher fatty acid utilization. It has also been reported that longterm consumption of chronic $\alpha$-glycosidase inhibitors improves lipid profiles in animal models of diabetes, suggesting that lower Very Low Density Lipoprotein (VLDL)-triacylglyceride secretion improves hyper triacylglyceridemia and hypercholesterolemia [9]. The chloroform extract of $C$. papaya leaf reduced fasting blood glucose levels in STZ-treated rats [10].

A study observed a higher hypoglycaemic effects when glibenclamide-pregnenolone was administered to alloxan treated rats, than glibenclamide alone. This study suggests that a steroid nucleus is important for a high hypoglycaemic effect of the glibenclamide-pregnenolone derivative, possibly conditioning the high degree of lipophilicity induced by it [11]. From the results 
obtained, it can be concluded that the hypoglycemic effect of $C$. papaya chloroform extract may be due to its phytoconstituents, especially steroids. The capability of the latter to slow glucose and lipid absorption in the digestive organs represents one of the therapeutic approaches used for the decrease of postprandial hyperglycemias. Taken together, the results suggest that the treatment with the chloroform extract of $C$. papaya could be beneficial in the treatment of hyperglycaemia and related hyperlipidemia in diabetes.

In conclusion, this study on C. papaya suggests that the high concentrations of steroids in C. papaya leaves could be responsible for the hypoglycemic and hypolipidemic effect of the chloroform extract in diabetic rats.

\section{Maringa Oleifera Lam}

The root extracts from moringaceae increased lipid peroxides, increased lL-6 and decreased antioxidant enzyme in the serum and kidney tissue homogenate compared to that of the negative control group. Lmmunoglobin ( $\lg A, \lg G)$, fasting blood sugar and glycosylated haemoglobin increased. Urine analysis showed glycosuria and increased potassium, sodium, creatinine, uric acid and albumin levels, kidney and pancreas tissues showed pathological alterations.

However, the pods extract from moringa oleifera lam causes reduction in serum glucose and nitric oxide with increased in serum insulin and protein levels, degenerative changes in beta-cells [12].

\section{Commiphora Africana (A Rich)}

This stems bark extract (alkaloids, tannins, flavonoids, steroids and saponin) causes decrease in the blood glucose level [12].

\section{Mimosa pudica L.}

These belong to the mimosacrae and its leave extract reduced blood glucose level and caused body weight increase [12].

\section{Albizia odoratissina Benth}

This is also mimosaceae its bark extract reduce the blood sugar and serum cholesterol level, triglycerides, serum glutamicoxaloacetic transaminase, serum glutamic pyruvic transaminase alkaline phosphatise and decrease level of total proteins [12].

\section{Coptis chinensis}

The chizomes of coptis chine sis are used in traditional Chinese medium and serve as a source for the isoquinoline alkaloids bebeerines, palmatine and cortisone [13]. A variety of pharmacological effects of coptis chine sis extracts or its chemical components have been reported, but the relevance of these in vitro and animal studies to human health are unknown.

\section{Panax ginseng Mey}

This is a Araliaceae, its root and plant extract (glycans, panaxans) lowers blood sugar levels [12]. The woody root extract causes decreased serum levels of Aspartate Amino Transferase (AST) Alanine Amino-Transferase (ALT), Gamma Glutamyl Transpeptidase (GGT) enzymes, Total Cholesterol (TC),triglycerides (TG), and low density lipoproteins (LDL-C) and improved atherogenic index. Blood glucose and leptons hormone decreased and increased activities of Superoxide Dismutase (SOD), Glutathione Peroxidise (GPx) and Catalase (CAT). Panax ginseng Mey woody root extracts (pioglitazone, repaglinide) stimulate an increase in insulin action and secretion, decrease in beta-cell mass. Its plant extracts acting like insulin and increasing insulin secretion from beta cells of pancreas.

Generally speaking, the consumption of photochemical is becoming increasingly acceptable in Asia and Africa especially in the treatment of diabetes [14], hypoglycaemic herbs are used in Chinese medicine to treat diabetes mellitus, Ginseng, bitter melon and Coptis chinensis are used in both types I and II diabetes.

The efficacy of hypoglycaemic herbs is achieved by increasing insulin secretion, enhancing glucose uptake by adipose and muscle tissues, inhibiting glucose absorption from intestine and inhibiting glucose production from hepatocytes [14] all these processes culminate in hypoglycaemia hence their hypoglycaemic effects should be well characterised by Ademolu's Classification of Hypoglycaemia (Table 1) before consumption for the safety of all especially the diabetic. Herb-drug interaction and herb-herb interaction is another concern.

Contrary to some beliefs, herbs can have side-effects. Unfortunately, herb-drug interactions in diabetic treatments have not been well documented.

Table 1: Ademolus Classifications of Hypoglycaemia.

\begin{tabular}{|c|c|}
\hline & Blood Sugar Level (mg/dl) \\
\hline GRADE 1(MILD) & $55-70$ \\
\hline GRADE 2(MODERATE) & $40-54.9$ \\
\hline GRADE 3(SEVERE) & $10-39.9$ \\
\hline GRADE 4(VERYSEVERE) & $<10$ \\
\hline $\begin{array}{c}\text { N:B Symptomatic Hypoglycaemia } \\
\text { above 70mg/dllS A Subset of } \\
\text { GRADE1 }\end{array}$ \\
\hline $\begin{array}{c}\text { N:B Asymptomatic Grade4 IS } \\
\text { Ademolus Phenomenon }\end{array}$ \\
\hline
\end{tabular}

A number of supplements are known to have intrinsic effects on serum glucose, for example, ginseng is hypoglycaemic in diabetic patients [14]. St John's Wort increases the apparent clearance of gliclazide an oral hypoglycaemic (anti-diabetic) classified as a sulfonylurea significantly.

\section{Conclusion}

Photochemical have divers effects on the internal milieu. It can enhance glucose breakdown causing hypoglycaemia. People living with Diabetes mellitus needs to be careful while consuming photochemical with hypoglycaemic effect as it can potentiate the effects of their medication either insulin or oral hypoglycaemic agent in causing hypoglycaemia. 


\section{References}

1. De D, Ali KM, Chatterjee K, Bera TK, Ghosh D (2012) Anti-hyperglycaemic and antihyperlipidemic effects of $n$-hexane fraction from the hydromethanolic extract of sepals of Salmalia malabarica in streptozotocininduced diabetic rats . J Complement Integr Med pp. 1553-3840.

2. Koehn FE, Carter GT (2005) The evolving role of natural products in drug discovery. Nat Rev Drug Discov 4(3): 206-220.

3. World Health Organization press (WHO) (2012) Traditional medicine strategy.

4. Isela E Juarez-Rojop, Carlos A Tovilla Z, Aguiilar-DL, Roa-dela FF, Leonor López-Meraz, et al. (2014) Phytochemical screening and hypoglycemic activity of Carica papaya leaf in streptozotocin-induced diabetic rats. 24(3): 341-347.

5. Azarkan A, Garcia-Pino R, Dibiani L Wyns, Loris RD, Baeyens-Volant D, et al. (2006) Crystallization and preliminary X-ray analysis of a protease inhibitor from the latex of Carica papaya. Acta Crystallogr Sect F Struct Biol Cryst Commun 62(12): 1239-1242.

6. Lim TK (2012) Carica papaya In: Edible Medicinal and Non-Medicinal Plants. Springer, pp. 693-717.

7. KH Miean, Mohamed S (2001) Flavonoid D (myricetin, quercetin, kaempferol, luteolin and apigenin) content of edible tropical plants. J Agric Food Chem 49(6): 3106-3112.

8. Sanders RA, Rauscher FM, Watkins JB (2001) Effects of quercetin on antioxidant defense in streptozotocin-induced diabetic rats. J Biochem Mol Toxicol 15(3): 143-149.

9. Standl E, Schnell O (2012) Alpha-glucosidase inhibitors: cardiovascular considerations and trial evaluation. Diab Vasc Dis Res 9(3): 163-169.

10. Kesari AN, Gupta RK, Watal G (2005) Hypoglycemic effects of Murraya koenigii on normal and alloxan-diabetic rabbits. J Ethnopharmacol 97(2): 247-251.

11. Figueroa-Valverde L, Díaz-Cedillo F, López-Ramos M, García-Cervera E, Pool-Gómez E, et al. (2012) Glibenclamide-pregnenolone derivative has greater hypoglycemic effects and biodistribution than glibenclamide- $\mathrm{OH}$ in alloxan-rats. Biomed Pap Med Fac Univ Palacky Olomouc Czech Repub 156(2): 122-127.

12. Govindappa M (2015) A Review on Role of Plant(s) Extracts and its Phytochemicals for the Management of Diabetes. J Diabetes Metab 6: 7.

13. Dr. Duke's Phytochemical and Ethnobotanical Databases.

14. Hui HX, Tang G, Go VL (2009) Hypoglycemic herbs and their action mechanisms. Chin Med 4:11.

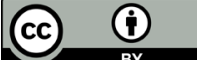

Creative Commons Attribution 4.0 International License

For possible submissions Click Here

\section{Submit Article}

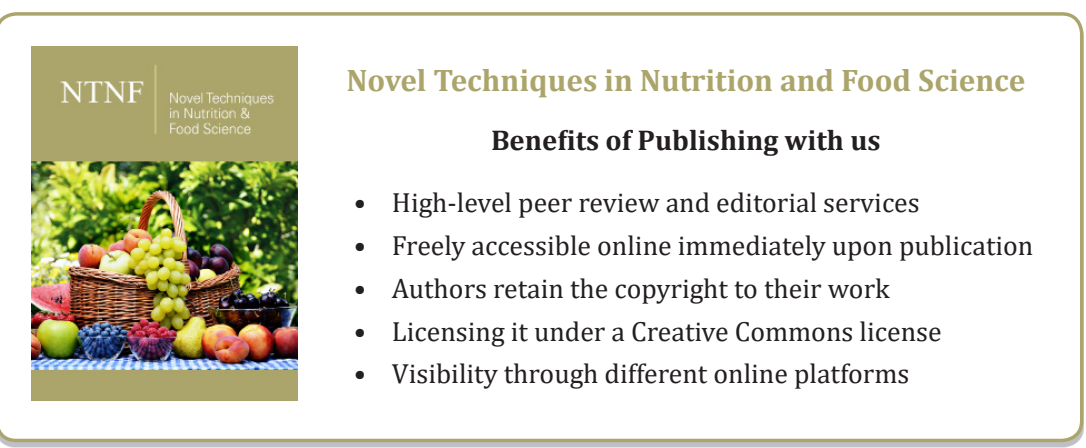

